\title{
DOI: 10.7596/taksad.v10i2.3022
}

Citation: Snikhovska, I., Glazunova, L., Soloviova, L., Tymchuk, O. (2021). The Role and Function of Ethnology in Developing the Aesthetic Competence of Philology Students in Ukraine. Journal of History Culture and Art Research, 10(2), 55-66. doi: http://dx.doi.org/10.7596/taksad.v10i2.3022

\section{The Role and Function of Ethnology in Developing the Aesthetic Competence:}

\section{A Case Study on Philology Students}

\author{
Irena Snikhovska ${ }^{1}$, Lesya Glazunova ${ }^{2}$, \\ Larysa Soloviova ${ }^{3}$, Olena Tymchuk ${ }^{4}$
}

\begin{abstract}
The article is devoted to the experimental testing of aesthetic competence of future philologists by means of ethnology. The principles (national character, humanization, ethnicization, cultural conformity, integration) are considered and stages of model implementation (orientative, training, creative) are elaborated and characterized. Structural and functional components, criteria and indicators of the levels of forming the future philologists' aesthetic competence are defined. The characteristic of levels of aesthetic competence development in philology students (reproductive, constructive, creative) is given. The characteristics of the levels with the help of the coefficient of tasks completeness related to knowledge, skills and abilities for aesthetic competence development of the philology students by means of ethnology were determined. The paper concludes by calling attention to the enhancement of the educational process forms and methods in order to develop the aesthetic competence of future philologists by means of ethnology, urging to instill the aesthetic competences more purposefully and integrally throughout the Bachelor program.
\end{abstract}

Keywords: Aesthetic Competence, Ethnology, Philology Students, Ethnological Means.

\footnotetext{
${ }^{1}$ Associate Professor, PhD in Philology, Zhytomyr Ivan Franko State University, https://www.orcid.org/00000001-6775-274X, E-mail: irena29@gmail.com

${ }^{2}$ Faculty Member of General Education, PhD in Pedagogics, Zhytomyr Cooperative College of Business and Law, https://www.orcid.org/0000-0001-6893-756X, E-mail: alesia2902@ukr.net

${ }^{3}$ Associate Professor, PhD in Philology, Polissia National University, https://www.orcid.org/0000-0001-55745251, E-mail: larisasolovyova23@gmail.com

${ }^{4}$ Associate Professor, PhD in Philology, Drohobych Ivan Franko State Pedagogical University, https://www.orcid.org/0000-0002-8514-1253,E-mail: olenatymchuk5@gmail.com
} 


\section{Introduction}

Currently, one of the defining strategic principles of educational policy in Ukraine is the humanization of education, which is based on nurturing moral and intrinsic values, encouraging the development of the individual's aesthetic culture. This requires the training of aesthetically competent philologists, able to envision the future perspectives and, at the same time, to respect and enrich the historical and cultural heritage of their people. It is aimed at ensuring this process, the ideas and provisions set out in the state regulatory documents on education in Ukraine. Among these are the following: the laws of Ukraine "On Education", "On Higher Education", the National Program "Education" (Ukraine of the XXI century), the National Strategy for Education Development in Ukraine for 2012-2021, etc. In particular, in the National Doctrine of Education Development in Ukraine in the XXI century, the emphasis is placed on determining the priority areas of education, namely, "implementation of the Doctrine will ensure the transition to a new humanistic and innovative philosophy of education, which will provide a significant increase in intellectual, cultural, spiritual and moral potential of society and the individual" (The National Doctrine).

Thus, the governmental documents of Ukraine emphasize the need to form aesthetic competence in the training of future specialists in philology at higher educational institutions (HEls). Today, the process of formation of aesthetic competence involves a qualitative change in the level of aesthetic culture of the future philologists, which can be an individual, a social group and society as a whole. It is a continuous process throughout a person's life, which resolves the contradictions between the level of aesthetic culture of mankind and an individual's culture throughout life. The purpose of the aesthetic competence development is to transfer the accumulated knowledge, to form the universal holistic culture of the personality, using various pedagogical forms and means. The forms of experience transfer can be diverse.

With this in mind, in HEls of Ukraine the educational process is aimed at the intellectual, comprehensive development of contemporary youth, the broadening of their worldview, enhancement of relevant personal and professional qualities. However, the development of the aesthetic sphere of future specialists calls for a closer attention. The formation of aesthetic competence of the young people is related to the meaningful teachers' activities and requires the philology students to be specially trained in aesthetic inquiry (llyenkov, 2007).

One of the effective means of developing the aesthetic competence of the future philologists is ethnography, which provides not only understanding, preservation, increase of folk spiritual and material values (Trautmann, 2006), but also encourages learners' own creative activity. In particular, Marini (2020) dwells on everyday aesthetics in education and in doing so, views aesthetics in the framework of philosophical aesthetics, which tends to look at sense perception as the backdrop of all experience (Marini, 2020).

The purpose of the study is to test experimentally the model of aesthetic competence formation of future philologists by means of ethnology. According to the purpose, the following tasks of research were defined: to analyze the state of research of the problem in the theory and practice of training philologists in Ukraine; to outline the essence of the basic concepts and categories of research; to study the state and impact of aesthetic competence formation as a component of the philology students' professional readiness.

The analysis of the literature on the research problem shows that its various aspects are reflected in the scientific works of a number of researchers. In modern educational theory and practice, the scientific background for a comprehensive study of the individual's aesthetic competence obviously is the research in the field of: philosophy (Johnson, 2019, Marini, 2006) and psychology (Murno, 1996; Scrutton, 1996), ethnography (Mytre, 2012), anthropology (Ochs 2012); professional training (Hobgood et al., 2006; Knipper, 2013; Vasiagina, 2019).

The study is based on the conceptual provisions of aesthetic personality development and takes a close look not only at the nature of the aesthetic experience but rather its moral and intrinsic value in our 
lives. Sheppard (1987) explores the nature of aesthetic experience, appreciation and evaluation. Lehrer (2011) examines the value of aesthetic expression against globalized background, as well as the forms of the aesthetic experience, intentionality, and the form of representation, arguing that art is inseparably connected to, not isolated from the way people think and feel, react and represent.

The present research draws on Glazunova's dissertation research (Glazunova, 2013), devoted to the problem of preparing future teachers for the formation of aesthetic worldview. This scope of research was also addressed by $\mathrm{O}$. Ihnatov, $\mathrm{M}$. Necheporenko, $\mathrm{O}$. Sofishchenko while studying the instilling the aesthetic values in students. The review of the scientific literature allowed us to conclude that the formation of aesthetic competence of the future philologist by means of ethnology is an indispensable component of the educational process in Ukrainian HEls.

At the present stage of society development, philological education is based on such conditions of teaching process as the understanding of logical ties between theoretical and practical training and the reflection of basic requirements for its organization (Ostapenko, 2012).

Given the aim of measuring the outcome, currently, we witness the educational paradigm shift which changes the perspective from structure- and process-based education towards competency-based one. The authors reviewed the existing literature to provide practical insight into how to accomplish full implementation and evaluation of the new paradigm.

Herewith training of philologists is an integral process and consists of certain elements, its purpose and tasks are caused by social requirements to their professional activity. There are a number of approaches to place and function of aesthetic educational training of a specialist, one of them is the competence approach.

Weinert (1999) emphasizes that the competence approach with due regard of linguistic competence, characterized as an integration of ethnological, psychological and sociological approaches, that have the capacity to bridge the gap between individual and collective competence models, taking into consideration the student's personality and with due respect to creative activity and selfdevelopment. Within the social and human sciences, one area undergoing rapid expansion and attracting increased public attention is empirical educational research.

As noted by Klieme, Hartig \& Rauch (2008), in the last few years the concept of competence has been used even more frequently. The task of the competence approach in professional education is the formation of key (basic) competences of the future specialist in a particular field. There are the following types of competences: cultural, informational, communicative, cognitive, social, etc.

The scientific research requires an analysis of its main categories, establishment of relationships between them, common and different, determination of one's own position on the use of terminology (Schneider, 2019). We determine the following basic concepts of our article: "competence", "aesthetic competence", "development of aesthetic competence", "development of aesthetic competence of a future philologist".

Dictionaries define the concept "competence" in the following way:

○ the ability to do something well (Cambridge Dictionary),

- " "the ability to do something well or effectively" (Collins Dictionary);

- "the quality or state of having sufficient knowledge, judgment, skill, or strength (as for a particular duty or in a particular respect), the knowledge that enables a person to speak and understand a language, a sufficiency of means for the necessities and conveniences of life also competency)" (Merriam Webster Dictionary);

- the ability to do something well; $f \mathrm{ml}$ a skill needed to do a particular job" (Longman Dictionary). 
Allen (2008) emphasizes the importance of cultural competency, including educational, instructional, psychological aspects.

In the documents of the International Commission of the European Council, the concept of competence is considered as "general or key skills, fundamental learning paths, key qualifications, cross-learning skills, key ideas, or basic knowledge" (Definition and Selection). Competences, according to experts of the Council of Europe, include the following characteristics: the ability of the individual to perceive and respond to individual and social needs; a set of attitudes, values, knowledge and skills (Council Recommendations, 2018; The European Qualifications Framework, 2008).

Summarizing the above, we can conclude that competence is characterized by the following features: a person's possession of relevant competencies, willingness to perform professional duties at the professional level; systemic entity, which contains a set of knowledge, skills, abilities and methods of activity. We believe it is appropriate to consider competence as the ability of an individual to effectively perform activities that involve the possession of knowledge, skills, abilities that allows their use in the successful task solution. In the course of our research, it is necessary to pay attention to the axiological, universal cultural, ethnocultural, multicultural and professional competence related to the aesthetic one.

In recent years, cultural competence has become a popular term to address the challenge of cultural diversity. The term "aesthetic competence" cannot be effectively perceived without taking into account such concepts as aesthetic culture, aesthetic education, aesthetic knowledge, aesthetic values, aesthetic perception, etc. Drawing on the definitions, we distinguish the notion of aesthetic competence as the ability of the individual to aesthetic perception and understanding of beauty, which involves the aesthetic knowledge, skills, abilities, formation of aesthetic judgments, feelings, values, ideals, behavior, etc. Cultural diversity poses challenges in the educational process for many reasons.

The development of aesthetic competence is a purposeful process of moulding a creatively active person who is capable to perceive, feel, appreciate life and art. Thus, we view the development of aesthetic competence of an individual as a complex integrated process aimed at revealing the motives, needs of professional activity, aesthetic perception and understanding of beauty, which involves aesthetic knowledge and allows a person to successfully carry out professional activities in a particular field.

The philologist must be a person with a developed philological culture as a part of the scientific worldview and holistic human culture and meet the following requirements: theoretical training and practical skills of understanding the laws of language development, language situation and national and world literature; high moral and ethical qualities, respect to culture and history of the country, tolerance to other nations.

\section{Methodology}

To achieve the goal and objectives, the following research methods were used:

o theoretical - analysis, synthesis, systematization, understanding and generalization of philosophical, psychological and pedagogical, ethnologic, cultural, methodical literature, pedagogical press, normative documents on the research problem;

o empirical - conversation, survey, pedagogical observation, questionnaires of students, the method of expert assessments to identify levels of students of the humanities aesthetic competence formation by means of ethnology;

- methods of mathematical statistics for quantitative and qualitative analysis of research results, statistical data processing, provided by the application of Fisher's analysis of variance and statistical Student's $t$-test, in order to substantiate the effectiveness of the author's model of the future philology teacher's aesthetic competence by means of ethnology.

The theoretical and experimental investigation was carried out in three stages. 
- At the $1^{\text {st }}$ stage (the theoretical stage), the state of problem research in philosophical, psychological, educational, ethnological, methodical literature is analyzed; the topicality is determined, the main areas, aim, tasks, object, subject are set; the basic concepts are specified; the program and research and experimental methodology are developed.

- At the $2^{\text {nd }}$ stage (the diagnostic stage), the structural and functional components, criteria, indicators and diagnostics of the levels of formation of the future philology teacher's aesthetic competence are outlined and systematized; the basic pedagogical conditions are clarified; the author's model is substantiated; the content, forms and methods of aesthetic competence formation means are developed; the ascertaining stage of the experiment was carried out.

- At the $3^{\text {rd }}$ stage (the generalizing stage), the authors' tools were implemented and their efficiency was experimentally tested; the obtained research results were presented.

The experimental research was carried out on the basis of Zhytomyr Ivan Franko State University. One hundred and twelve students of Educational and Research Institute of Foreign Philology were engaged in the experimental work.

The research model contains the purpose, pedagogical conditions, structural and functional components, criteria and levels of formation of aesthetic competence of philology students by means of ethnology, as well as the stages of model realization (Glazunova, 2013). The said model was adjusted to meet the objectives of the present article.

The pedagogical conditions of formation of aesthetic competence of the future philologist by means of ethnology are singled out and substantiated, in particular, orientation of educational process at HEls to the use of relevant ethnological means of illustrative, informative and practical type for the development of positive motivation.

\section{Results}

The experimental research was conducted in 2019-2020 academic year. It included ascertaining and formative stages. 112 students of philology took part in the formative stage of the experiment, 58188 of them in the experimental group (EG) and 54174 in the control group (CG). Input diagnosis revealed the initial level of aesthetic competence formation of students-philologists by means of ethnology. The results of the research indicate that students of both groups had approximately the same level of its formation. In particular, in EG - creative level was marked by $17.3 \%$ (CG - 14.9\%), constructive-search - EG - 43.1\% (CG - 51.8\%), intuitive-reproductive - EG - 39.6\% (CG -33.3\%). In addition, the results of the ascertaining stage of the experiment confirmed the need to implement the author's model.

In the EG, the model was implemented, in particular, through teaching the disciplines Communicative strategies of the foreign language where the elements of Linguistic Countrystudy, in particular, ethnocultural vocabulary was analyzed, during the course of the Study Practice. In the CG, the elements of the proposed model were used in a concise version with a selective teaching of some topics.

After the implementation of the model, the output diagnosis of indicators of the formation of aesthetic competence of students of philology in the experimental and control groups was conducted. The results of comparative analysis indicate a positive trend in the experimental group: creative level - EG $-46.6 \%$ (CG - 22.3\%), constructive- EG - 43.1\% (CG - 48.1\%), reproductive - EG - 10.3\% (CG - 29.6\%) (Table 3).

The reliability of the results of the research was ensured by applying the methods of variance analysis by R. Fisher and the statistical Student's t-test. It is proved that the indicators of the levels of formation of aesthetic competence of the students of the experimental group increased significantly in comparison with the results in the control group.

\section{Discussion}


While conducting the research, the questionnaires (Table 1, Table 2) were conducted, the results were processed and in the students' answers there is an obvious focus on learner autonomy principles and student-oriented approach (Antyushina et al, 2021) to organizing the educational and teaching process, the necessity to achieve cooperation in the system "teacher-student", involving the students in the process of forming the aesthetic culture, behavior, developing the relevant abilities and creative activities. The emphasis was placed on the importance of creating a favorable atmosphere, fostering respect to other cultures and nations. There is an absolute need to thorough study the native language, respect for one's own culture and Ukrainian folk traditions.

It was found that the effectiveness of modern higher education depends, in particular, on the application of an integrated approach to the selection and use of methodologically appropriate forms and methods of forming students' aesthetic competence, which is based on ethnologic basis and provides comprehensive use of appropriate means in educational and extracurricular activities.

We identified and substantiated the relevant pedagogical conditions. Taking them into account makes the process of forming the future philologist's aesthetic competence, in our opinion, more effective:

$\circ$ orientation of the educational process of higher educational institutions on the formation of aesthetic competence of the future philologist;

o purposeful formation of positive motivation to use the means of ethnology as illustrative, informative and practical material;

o inclusion of the future philologist in the system of aesthetic culture formation, aesthetic behavior, development of aesthetic abilities to one's own creative activity;

$\circ$ an integrated approach to the selection and application of methodologically appropriate forms and methods of forming the students' aesthetic competence, which are based on ethnologic basis and ensures the adequacy of educational and extracurricular activities of philology students.

In the ascertaining experiment of our research, 112 full-time and part-time philology students were involved. The purpose of the ascertaining experiment was to determine the levels of formation of aesthetic competence development of the philology students by means of ethnology. In accordance with the goal, the following main tasks were set:

- to determine the level of aesthetic competence of philology students, to check their readiness to use the means of ethnology in professional activities;

to elaborate on the criteria, indicators, levels of aesthetic competence development of the future philologists.

The first step of the ascertaining stage of the experiment was to determine the level of aesthetic competence development of students of philology, identify general knowledge about aesthetic education, aesthetic culture, aesthetic consciousness, behavior, values, ideals, knowledge of ethnology and its use in the educational process, etc. For this purpose, a questionnaire was conducted (Table 1 , Students' Questionnaire 1).

Table 1. Students' Questionnaire 1. Determination of the Most Effective Pedagogical Conditions for the Formation of Aesthetic Competence of the Philology Students by Ethnological Means

\begin{tabular}{|l|l|l|}
\hline No. & \multicolumn{1}{|c|}{ Pedagogical prerequisites } & $Y / N$ \\
\hline 1 & $\begin{array}{l}\text { Orientation of the educational process of higher educational institutions on the } \\
\text { formation of aesthetic competence of the philology student. }\end{array}$ & \\
\hline 2 & $\begin{array}{l}\text { Harmony of activity in the system "teacher-student" on the basis of democratic } \\
\text { style of communication. }\end{array}$ & $\begin{array}{l}\text { The purposeful formation of positive motivation to use the means of ethnology } \\
\text { of illustrative, informative and practical material. }\end{array}$ \\
\hline 3 &
\end{tabular}




\begin{tabular}{|l|l|l|}
\hline 4 & $\begin{array}{l}\text { Inclusion of the future philologist in the system of formation of aesthetic } \\
\text { culture, aesthetic behavior, development of aesthetic abilities to one's own } \\
\text { creative activity. }\end{array}$ & \\
\hline 5 & $\begin{array}{l}\text { Formation and development of creative attitude of philology students to any } \\
\text { kind of activity. }\end{array}$ & $\begin{array}{l}\text { Implementation of an integrated approach to the selection and application of } \\
\text { methodologically appropriate forms and methods of formation of students' } \\
\text { aesthetic competence which is based on ethnologic basis and ensures the } \\
\text { adequacy of educational and extracurricular activities of philology students. }\end{array}$ \\
\hline 6 & $\begin{array}{l}\text { Due regard to the level of teacher's aesthetic competence, the creativity of } \\
\text { their pedagogical activity. }\end{array}$ & \\
\hline 7 & $\begin{array}{l}\text { Creation of an environment for the development of each individual regardless } \\
\text { of their nationality, promotion tolerance towards other cultures and nations. }\end{array}$ & \\
\hline 8 &
\end{tabular}

The results of the survey were as follows. The majority of students did not formulate an opinion on the question which person can be called competent (42.2\%), $14.5 \%$ of students only were able to give the correct answer. This indicates that using the concept of "competence", students do not fully understand its meaning or do not use this term at all. Thus, $11.3 \%$ of students were able to define the concept of "aesthetic competence". By this term, most students of philology means "possession of a person of certain aesthetic knowledge, aesthetic values, good taste, etc." Future philologists understand the definition, but cannot explain it. This indicates that they lack information on this issue.

Table 2. Students' Questionnaire 2. The Role and Place of Ethnological Means in the Development of Aesthetic Competence of a Philology Student.

\begin{tabular}{|c|c|}
\hline No. & Survey Questions \\
\hline 1 & In your opinion, what kind of a person can be called competent? \\
\hline 2 & How do you understand the term "aesthetic competence"? \\
\hline 3 & What are the levels of aesthetic competence formation? \\
\hline 4 & $\begin{array}{l}\text { What levels of the process of aesthetic competence formation would you personally } \\
\text { distinguish? }\end{array}$ \\
\hline 5 & What means can be used to form the aesthetic competence of the personality? \\
\hline 6 & Provide some examples of ethnological means. \\
\hline 7 & $\begin{array}{l}\text { Which ethnological means do you consider the most appropriate in the process of } \\
\text { forming aesthetic competence? }\end{array}$ \\
\hline 8 & $\begin{array}{l}\text { Give the examples of researchers who believed that the ethnological means are } \\
\text { essential in the personality development. }\end{array}$ \\
\hline 9 & $\begin{array}{l}\text { In your opinion, within the framework of which disciplines it is desirable to implement } \\
\text { the development of aesthetic competence of youth by means of ethnology? }\end{array}$ \\
\hline 10 & $\begin{array}{l}\text { Do you consider it necessary in training of future philologists to shape their aesthetic } \\
\text { competence by means of ethnology? }\end{array}$ \\
\hline
\end{tabular}

Students of philology could not correctly describe the features of an emotional and sensory level of aesthetic competence formation (22.6\% of students gave the wrong answer), in our opinion, because this issue is considered in the educational process indirectly. The majority of students (55.4\%) do not know by what means it is possible to form aesthetic competence of a person. When asked to list the known means of ethnology, they mentioned: folklore, customs, folk crafts. This indicates that students lack information about the means of ethnology, the possibility and effectiveness of their use in the 
educational process in order to form aesthetic competence. Future philologists could not provide the scholars' names who believed that the means of ethnology are important in moulding a personality. It can be concluded that little attention is paid to this issue in teaching of the humanities. The vast majority of students (78.5\%) consider it necessary to form the aesthetic competence of young people by means of ethnology while studying subjects of the humanities. This indicates that they are ready for this process, want to improve, increase the level of aesthetic competence, learn more about the means of ethnology and the effectiveness of their use in the educational process.

The structural (emotional, diagnostic, practical, evaluative) and functional (motivational, organizational, monitoring) components of the model of aesthetic competence formation of the future philologist by means of ethnology are represented and indicated.

In accordance with the purpose of the research at this stage, we have determined the criteria, indicators and levels of aesthetic competence development of future philologists. This was the second step of the ascertaining experiment. We distinguished an emotional criterion, a cognitive criterion, an effective criterion. The formation of aesthetic competence of the future philologists by means of ethnology is a complex and multifaceted process. Based on the above criteria, it is expedient to distinguish the following levels: a reproductive level, a constructive level, a creative level.

Table 3. Dynamics of formation of philology students' aesthetic competence by means of ethnology in experimental and control groups at the beginning and at the end of the formative stage of experiment.

\begin{tabular}{|c|c|c|c|c|c|c|c|c|}
\hline \multirow{3}{*}{$\begin{array}{ll}\text { Levels } & \text { of } \\
\text { formation } & \text { of } \\
\text { aesthetic } & \\
\text { competence } & \text { of } \\
\text { philology } & \\
\text { students } & \text { by } \\
\text { ethnology } & \end{array}$} & \multicolumn{4}{|c|}{ The beginning of the experiment } & \multicolumn{4}{|c|}{ End of experiment } \\
\hline & \multicolumn{2}{|l|}{ EG } & \multicolumn{2}{|l|}{ CG } & \multicolumn{2}{|l|}{ EG } & \multicolumn{2}{|l|}{ CG } \\
\hline & $\mathrm{N}$ & $\%$ & $\mathrm{~N}$ & $\%$ & $\mathrm{~N}$ & $\%$ & $\mathrm{~N}$ & $\%$ \\
\hline Reproductive & 23 & 39.6 & 18 & 33.3 & 6 & 10.3 & 16 & 29.6 \\
\hline Constructive & 25 & 43.1 & 28 & 51.8 & 25 & 43.1 & 26 & 48.1 \\
\hline Creative & 10 & 17.3 & 8 & 14.9 & 27 & 46.6 & 12 & 22.3 \\
\hline Total & 58 & 100 & 54 & 100 & 58 & 100 & 54 & 100 \\
\hline
\end{tabular}

1. Indicators of an emotional and sensory criterion: the level of formation of emotional reaction to the use of ethnologic means in the process of forming aesthetic competence; the presence of students' formed aesthetic feelings, tastes and ideals; instilling aesthetic values, the ability to give an aesthetic assessment; harmonious development of personality by means of ethnology in the process of aesthetic competence development. After analyzing the results of the questionnaire and calculating the coefficient of their significance, we can conclude that a constructive level is overall dominated by an emotional criterion $-54.6 \%$ in the group of future philologists, a large percentage of respondents $(25.2 \%)$ demonstrates a creative level and $20.2 \%$ - a reproductive level.

The students' survey showed that the majority of future philologists (44.7\%) believe that the process of aesthetic competence development is a component of the emotional sphere of an individual. The students involved in the experiment support the opinion that in the process of forming aesthetic competence, the personality's creative imagination and intuition, developed creative thinking, a high 
level of creative potential are of paramount importance. Among the respondents $44.8 \%$ showed a creative level and $21.2 \%$ - a reproductive level. $42.4 \%$ of respondents have their own aesthetic values, standards, tastes in folk music, painting, handicrafts. The information obtained shows that students have their own aesthetic tastes, values, preferences, but do not know how these can be applied in the process of forming aesthetic competence.

The majority of future philologists $(52.9 \%)$ support the hypothesis that the emotional sphere of personality should be developed and enriched by the formation of aesthetic competence by means of ethnology, but do not know how to implement it. In fact, $50.4 \%$ of respondents have a positive attitude to the aesthetic works of folk artists, i. e. they are interested in studying the means of ethnology. Further, $41.4 \%$ of students need to develop the emotional sphere, self-education and increase the level of aesthetic competence through ethnology, in addition, the vast majority of respondents $(51.7 \%)$ believe that it is necessary to instill aesthetic values. In determining an emotional criterion, we found that a large number of philology students $(54.6 \%)$ have a constructive level of aesthetic competence formation. They get aesthetic pleasure from contemplation, the study of ethnology, have their own aesthetic values, tastes, priorities, but do not know how to apply them in the process of aesthetic competence development.

2. Indicators of a cognitive criterion: level of aesthetic knowledge, skills and abilities, their awareness, system, development of abilities; capability to effectively choose and use the acquired knowledge, skills, abilities, skillful use of ethnological means; the desire for self-realization in professional activities, the need for self-education and increasing the level of aesthetic competence.

Having processed the survey data, we can conclude that a reproductive level of aesthetic competence formation by means of ethnology within the cognitive criterion (48.8\%) dominates in the group of future philologists. Compared to other criteria a quite low creative level (16.4\%) was found. This allows us to conclude that students have only some unsystematic knowledge of the use of ethnographic means in the aesthetic competence development. The significant share of students $(21.6 \%)$ do not know in what way the development of aesthetic competence by means of ethnology is specific, this yielded the following results: $43.7 \%$ of respondents demonstrated a reproductive level, $38.9 \%-$ a constructive level and $17.4 \%$ - a creative level. All in all, students have some knowledge of the ethnological means, but do not know how to use them in practice, what methods and forms of work will be effective. This indicates that the current level and content of training the philology students in the process of teaching the humanities has some drawbacks, which in turn lead to an insufficient level of developing the aesthetic competence of the future philologists.

3. Indicators of an effective criterion: critical judgments about one's own level of aesthetic competence, self-assessment of creative achievements; ability to self-esteem, self-knowledge, professional self-improvement, and increase the level of aesthetic competence; ability to reflexive analysis of ethnologic means, analysis and selection of the feasible methods and ways of forming aesthetic competence. The results of determining the level of aesthetic competence development of philology students by means of ethnology according to the effective criterion were distributed as follows: a reproductive level was determined by $16.4 \%$ of respondents, a constructive $-53.5 \%$, a creative $-30.1 \%$.

When studying the criticality of judgments about their own level of aesthetic competence, when conducting self-assessment of creative achievements $54.6 \%$ of respondents yielded a constructive level, $36.5 \%$ - a creative level and $8.9 \%$ - a reproductive level. The majority of respondents $(53.2 \%)$ defined their level of aesthetic competence as "sufficient", $40.8 \%$ - as "high" and only $6 \%$ - as "low". This indicates a sufficient level of self-criticism of students.

The results of the following question are interesting for comparison: "What is the level of aesthetic competence of a modern philologist?" The results were distributed as follows: $57.6 \%$ of respondents defined the level of aesthetic competence of a modern philologist as "sufficient", $37.5 \%$ - as "high" 
and $4.9 \%$ - as "low". Thus, students see the possibility of correction and increase the level of aesthetic competence in the educational institution.

It can be concluded that students are ready to study the means of ethnology and increase the level of aesthetic competence. The ascertaining experimental research proved that each of the defined levels of aesthetic competence development of the future philologist by means of ethnology (reproductive, constructive, creative) is characterized by quantitative indicators. We determined the characteristics of the levels with the help of the coefficient of completeness of tasks related to knowledge, skills and abilities for aesthetic competence development of the individual by means of ethnology.

\section{Conclusion}

The results of the research proved that in Educational and Research Institute of Foreign Philology the process of students' aesthetic competence development by means of ethnology should be devoted more attention. It is expedient to find the ways of improving the educational process in order to develop the aesthetic competence of future philologists by means of ethnology.

Along with that, the results of the ascertaining experiment showed that students of philology are eager to increase the level of aesthetic competence by means of ethnology in the study of humanities, but this is not possible without the specifically-designed training to provide them with the sufficient level of knowledge, skills and abilities.

The most appropriate means of ethnology in the process of forming the students' aesthetic competence are folklore, folk crafts, reviving folk traditions, learning about household items (clothing, utensils). The expedient forms of work for the development of students' aesthetic competence are the use of visual and methodological materials (artworks of folk craftsmen, visiting art galleries, screening relevant videos), virtual excursions to ethnologic and English museums, organizing ethno-parties, a project work "An audio guide to renowned ethnological places". It is expedient to use the results obtained while teaching the disciplines Linguistic Countrystudy, Ethnolinguistics, Sociolinguistics and Pragmatics of Translation.

\section{References}

Allen, D. (2008). Cultural competency training in a global society. New York: Springer.

Artyushina, G., Zgurbenko, N., \& Sheypak, O. (2021). Individual educational path based on learning styles theory as a way to reach sustainable quality education goals. Revista Inclusiones, 8(1), 54-66.

Cambridge Dictionary. Available at: https://dictionary.cambridge.org

Collins Dictionary. Available at: https://www.collinsdictionary.com

Council Recommendation on Key Competences for Lifelong Learning. (2018). Available at: https://ec.europa.eu/education/sites/education/files/recommendation-key-competences-lifelonglearning.pdf

Definition and Selection of Competencies (n. d.). Theoretical and Conceptual Foundations (DESECO). Strategy Paper on Key Competencies. An Overarching Frame of Reference for an Assessment and Research Program - OECD. Available at: http://www.deseco.admin.ch

Helth, P. (2019). Aesthetic-based competences lead to a sustainable learning practice: Re-thinking public management through the lens of sustainability. Local Economy, 34(6), 607-617. doi:10.1177/0269094219882859 
Hobgood C.; Sawning S.; Bowen J., \& Savage K. (2006). Teaching culturally appropriate care: a review of educational models and methods. Acad Emerg Med, 13, 1288-1295.

Ilyenkov, E. V. (2007). A Contribution to a Conversation About Esthetic Education. Journal of Russian and East European Psychology, 45(4), 81-84. http://doi.org/10.2753/RPO1061-0405450408

Johnson, M. (2019). The Aesthetics of Meaning and Thought: The Bodily Roots of Philosophy, Science, Morality, and Art. University of Chicago Press. http://doi.org/10.7208/9780226539133

Glazynova. L. A. (2013). The Formation of the Future Philology Teacher's Aesthetic Competence by Means of Ethnology, PhD thesis (Pedagogics). Zhytomyr. (In Ukrainian).

Klieme, E., Hartig, J., \& Rauch, D. (2008). The concept of competence in educational contexts. In J. Hartig, E. Klieme, \& D. Leutner (Eds), Assessment of competencies in educational contexts (pp. 3-22). Hogrefe \& Huber Publishers.

Knipper, M. (2013). Joining ethnography and history in cultural competence training. Cult Med Psychiatry, 37, 373-384.

Lehrer, K. (2011). Art, Self and Knowledge. Oxford University Press.

Longman Dictionary of Contemporary English. (n. d.). Available at: https://www.Idoceonline.com/dictionary/competence.

Marini, G. (2006). An Introduction to Everyday Aesthetics in Education. Studies in Philosophy and Education, 2, 1-12. https://doi.org/10.1007/s11217-020-09740-x

Merriam Webster Dictionary (n. d.). Available at: https://www.merriam-webster.com

Murno, Th. (1996). Art Education. Its Philosophy and Psychology. Selected Essays. New York.

Myhre, K. C. (2012). The pitch of ethnography: Language, relations, and the significance of listening. Anthropological Theory, 12(2), 185-208. https://doi.org/10.1177/1463499612454990.

Ochs, E. (2012). Experiencing language. Anthropological Theory, 12(2), 142-160. doi:10.1177/1463499612454088.

Ostapenko, S. (2012). Didactic conditions of formation of social competence of students of philological specialties in the process of independent educational activity. Scientific notes of Nizhyn State University named after M. Gogol, Psychological and pedagogical sciences, 1, 164-167. (In Ukrainian)

Schneider, K. (2019). What Does Competence Mean? Psychology, 10, 1938-1958. doi: $10.4236 /$ psych.2019.1014125

Scrutton. R. (1989). Modern Philosophy and the Neglect of Aesthetic. The Symbolic Order / ed. by P. Abbs. London.

Sheppard, A. (1987). Aesthetics: An Introduction to the Philosophy of Art. Oxford University Press. Available at: https://doi.org/10.2307/432002

The European Qualifications Framework for Lifelong Learning (2008). Luxembourg: Office for Official Publications of the European Communities. Available at: https://ec.europa.eu/ploteus/sites/eaceqf/files/leaflet_en.pdf. 
The National Doctrine of Education Development in Ukraine in the XXI century (2002). Retrieved from: https://zakon.rada.gov.ua/laws/show/347/2002\#Text

Trautmann, T. R. (2006). Languages and nations: the Dravidian proof in colonial Madras. Yoda Press.

Vasyagina, N. N., Eromasova, A. A., Kutbiddinova, R. A., \& Sergeeva, N. N. (2019). Ethno-cultural competence of educational psychologists. The European Proceedings of Social \& Behavioural Sciences, 755-762.

Weinert, F. E. (1999). Concepts of Competence. Definition and Selection of Competencies: Theoretical and Conceptual Foundations (DeSeCo). Neuchatel: Bundesamt für Statistik, 3-34. 